\title{
PROCESSO DE REGIONALIZAÇÃO DO NOROESTE FLUMINENSE
}

\author{
Regionalization Process of the Northwest Fluminense \\ Proceso de Regionalización del Noroeste Fluminense
}

Isis Marinho

Professora da Rede Municipal de Teresópolis

geoisis@hotmail.com

Artigo recebido em 31/08/2017 e aceito para publicação em 06/12/2017

DOI: $10.12957 /$ tamoios.2017.30212

\section{RESUMO}

O artigo analisa o processo de regionalização da Região Noroeste Fluminense, com o objetivo de expor ações de hegemonias de poder do capital na produção e reprodução do espaço. Entendendo a região como um instrumento de ação e intervenção política, segundo a abordagem regional do materialismo histórico e dialético, destaca como índios Puri, Coroado e Coropó perderam o direito sobre as terras locais através de expansão da fronteira agrícola em consonância direta com o Estado e a Igreja Católica. Destaca ainda a importância desses índios na relação com as frentes de colonização para o estabelecimento da fronteira regional. Segue expondo como produtores agropecuários e agentes políticos locais se apropriam de reificações para caracterizar a região, visando angariar verbas do Governo Federal e reproduzir suas ações hegemônicas; racionalizando o espaço a serviço da reprodução do capital. Através das causas estruturantes dessa caracterização regional, o artigo expõe como a Região Noroeste Fluminense foi reificada pela pujança e fertilidade, pela cafeicultura de produção nacional, pela pobreza e carência de recursos públicos e pela agricultura familiar.

Palavras-chave: Região Noroeste Fluminense; Regionalização; Reificação.

\section{ABSTRACT}

The article analyzes the regionalization of the Northwest Fluminense Region. Its purpose is to expose hegemonies of capital power in the production and reproduction of space. It affirms the region as an instrument of action and political intervention, according to the regional approach of historical and dialectical materialism. It emphasizes how Indians Puri, Coroado and Coropó lost the right on the local lands through expansion of the agricultural frontier in direct partnership with the State and the Catholic Church. It also highlights the importance of these Indians in the relationship with the fronts of colonization to establish the regional border. It exposes how agricultural producers and local political agents rationalize space at the service of capital, reify the region to raise funds from the Federal Government and reproduce their hegemonic actions. Through the structural causes of this regional characterization, the article describes how the Northwest Fluminense Region was reified: by the vigor and fertility, the coffee production of national production, poverty and lack of public resources and family farming.

Key words: Region of Northwest Fluminense; Regionalization; Reification. 


\section{RESUMEN}

El artículo analiza la regionalización de la Región Noroeste Fluminense, con el objetivo de exponer hegemonías de poder del capital en la producción y reproducción del espacio. En cuanto a la región como un instrumento de acción e intervención política, según el enfoque regional del materialismo histórico y dialéctico, destaca como indios Puri, Coroado y Coropó perdieron el derecho sobre las tierras locales a través de la expansión de la frontera agrícola en consonancia directa con el Estado y la Iglesia Católica. Destaca la importancia de esos indios en la relación con los frentes de colonización para establecimiento de la frontera regional. Expone como productores agropecuarios y agentes políticos locales se apropia de reificaciones para caracterizar la región, con el objetivo de recaudar fondos del Gobierno Federal y reproducir sus acciones hegemónicas; racionalizando el espacio al servicio de la reproducción del capital. A través de las causas estructurantes de esta caracterización regional, el artículo describe cómo la Región Noroeste Fluminense fue reificada por la pujanza y fertilidad, por la cafeicultura de producción nacional, por la pobreza y carencia de recursos públicos y por la agricultura familiar.

Palabras clave: Región Noroeste Fluminense; Regionalización; Reificación. 


\section{INTRODUÇÃO}

O estudo regional, na Geografia, remete a consideração de formas-conteúdo do espaço. Entrementes, o artigo, derivado de pesquisa de mestrado, direciona a abordagem regional a um instrumento de ação e intervenção política, corroborando com Gramsci que reconhece na abordagem regional a "organização e reprodução (...) dos grupos sociais (...), dentro do materialismo histórico" (HAESBAERT, 2010, p.54).

$\mathrm{O}$ artigo é organizado sob três eixos. Primeiro sob o histórico da organização e reprodução de grupos sociais da Região Noroeste Fluminense, que considera o pertencimento de área aos índios Coroado, Coropó e Puri. A partir das frentes de ocupação portuguesa, a região, também, "encontrava-se entre as áreas proibidas pelas cartas régias que objetivavam coibir o contrabando aurífero" das Minas Gerais (MALHEIROS, 2008). Assim, esse mesmo recorte de área sofreu incursão de missionários capuchinhos e forças militares, para o combate dos garimpos ilegais e controle das terras indígenas.

Segundo, discorre sob a denominação regional de "fronteira agrícola da Baixada Campista"; que experimentou ascensão econômica com a produção do café, tendo o município de Itaperuna como maior produtor de café do Brasil desde 1920 (CRUZ, 2003). No decorrer da década de 70 a área considerada se firmou com a produção de derivados do leite, sendo, até hoje, a maior bacia leiteira do Estado do Rio de Janeiro (ERJ). E tornou-se referência na produção de tomate, visto que em 1990, Cambuci estava entre os maiores produtores de tomate do Estado do Rio de Janeiro. Há de se acrescentar que a região, também, concentra atividades industriais de extração mineral não metálico (rochas ornamentais e produção de cimento especificamente).

Terceiro, expõe que com políticas de desenvolvimento regional a área passa a ser referida institucionalmente à função de "vocação" agroalimentar, principalmente na década de 1990 sob a gestão de Marcelo Alencar (1995-1998). Políticas essas, fomentadas pelo empresariado regional e pelos sindicatos patronais através da Federação das Indústrias do Estado do Rio de Janeiro (FIRJAN), por uma parceria público-privada. Assim, a Região Noroeste Fluminense é comumente reificada em trabalhos acadêmicos e em documentos oficiais do ERJ (de planejamento) como uma região pobre e carente de investimentos econômicos e sociais. Agregada a tal referência regional está à denominação "agricultura familiar".

Sobre dados estatísticos reunidos pelo IBGE no censo agropecuário de 2006 a Região Noroeste Fluminense é a região do Estado do Rio de Janeiro que possui maior concentração de população ocupada no setor agropecuário; em comparação com outras regiões do ERJ. Levando em conta principalmente a zona rural do Estado é a que mais concentra terras ${ }^{1}$. É o território rural ${ }^{2}$ do Estado do Rio de Janeiro com maior percentual de extrema pobreza ${ }^{3}$. E é a região que tem o menor PIB municipal em todo ERJ de 2006 até 2010.

Por sua vez o artigo considera como a organização e reprodução de grupos sociais regionais, incluso sociedade política e sociedade civil ${ }^{4}$, participaram do processo de regionalização do "Noroeste Fluminense" e na atribuição de significantes e significados regionais.

\section{REGIONALIZAÇÃO DO NOROESTE FLUMINENSE - E O ESPAÇO DE PERTENCIMENTO DOS ÍNDIOS COROADO, COROPÓ E PURI}

A Região Noroeste Fluminense é uma unidade de relações socioespaciais, inclusive, temporais. Considerando o nível de ação operacional entre grupos indígenas e 
frentes de colonização da coroa portuguesa, far-se-á referência às representações do espaço que lhe são ligadas. Para tanto, trechos históricos foram resgatados do trabalho de Malheiros (2008), a fim de compor o quadro de análise.

A área correspondente a Região Noroeste Fluminense foi habitada por índios Puri e Coroado - pertencentes ao grupo linguístico Macro Jế $\hat{e}^{6}$ Os índios Puri, em especial, estabeleceram uma rede de sociabilidade através de suas "comunidades multilocais" na área compreendida entre o mar e a margem norte do Rio Paraíba do Sul, projetando-se para oeste até o Rio Pomba em Minas Gerais, e Rio Itabapoana no Espírito Santo. Os índios Coroado, diferente dos índios Puri, habitavam os vales do Rio Paraíba do Sul, Pomba e Preto. Assim, projetando a fronteira administrativa da Região Noroeste Fluminense, recortando a prática de fluxo e estabelecimento de tais grupos indígenas, o "Noroeste Fluminense" era habitado praticamente pelos índios Puri e Coroado. Os Coropó provenientes do atual Estado de Minas Gerais, também, habitaram a área em aldeias-missões de capuchinhos italianos instaladas em São Fidélis, Itaocara e Santo Antônio de Pádua. Registros indicam que os índios Coropó, na aldeia-missão de São Fidélis, posicionavam-se à margem direita do Rio Paraíba do Sul até o Rio Pomba, para indicar marco de separação da margem esquerda - onde os índios Puri predominavam (MALHEIROS, 2008).

Os índios Puri, Coroado e Coropó, por volta de 1760, encontravam-se em meio a duas significativas frentes de expansão colonial: uma provinda da baixada campista até as margens do Rio Muriaé e em menor medida direcionada ao Rio Pomba; e a outra proveniente da Zona da Mata de Minas Gerais, que passa a ocupar o Rio Pomba (MALHEIROS, 2008, p. 152). Gradativamente com o avanço da fronteira agrícola, índios Puri, que tinham como hábito, em seu cotidiano, passar a maior parte do tempo em caçadas e em visitas a parentes, estabeleceram relações sociais com as fazendas na localidade. Observe registro de Frei Ângelo Maria de Luca, missionário capuchinho, sobre o contato dos índios Puri com um estabelecimento rural nas margens do Rio Muriaé, através do feitor da fazenda, em 1788:

\begin{abstract}
havia já bastante tempo que corria a fama que estavam sahindo, de tempos em tempos, no povoado à margem do rio Muriahé, umas tropas de índios, sem commeter hostilidades algumas, dando antes signal de paz e de quererem humanizar. (...) Resolveram então pedir a José Dias, que era então feitor na fazenda aonde eles apareciam, cujo dono era o capitão Braz Carneiro Leão, morador na cidade do Rio de Janeiro, resolveram de pedir então que logo que aparecessem os índios, lhes mandasse recado. (...). Appareceram finalmente um número de cinquenta pouco mais ou menos, no dia 29 do seguinte mez de agosto. Todos eram nus, sem amparo de sorte alguma, não estranharam o padre, a quem nunca tinham visto, mas antes mostraram-lhe muito agrado, especialmente por umas saias e ceroulas que lhes deu; em correspondência do que fizeram-lhe seus presentes de caças e fructas de sapucaia que tinham consigo. (LUCCA; CAMBIASCA: 29,30. Apud. MALHEIROS, 2008, p. 153).
\end{abstract}

É provável que rotas dos índios Puri, entre caminhos abertos da região do mar até cercanias do Rio Pomba em Minas Gerais e do Rio Itabapoana no Espírito Santo, foram absorvidas por ocupantes locais. Malheiros (2008, p. 316-318,320) aponta que missionários em São Fidélis registraram que em seu apostolado pelos "sertões" contaram com auxílio de guias negros, conhecedores dos "caminhos dos índios". Expõe que Frei Ângelo informou, em 1791, que na fazenda do Senhor Alferes João Luiz Machado, no Muriaé, onde pretendia estabelecer uma aldeia para os Puri, estes “(...) índios (...) estavam espalhados pelas senzalas dos escravos e pelas capoeiras desta fazenda". Ainda, "Negros fugidos das fazendas de Campos dos Goytacazes e das 
cercanias do rio Muriaé buscavam abrigo no espaço de domínio dos Puri. Constatando convivência pacífica entre eles devido à aproximação dos Puri com as fazendas". A autora ainda destaca que o proprietário de uma fazenda, a margem do Rio Paraíba, mandou 'chamar' um grupo Puri, que vivia nas vizinhanças, ao saber do interesse do naturalista príncipe Maxmilian.

$\mathrm{O}$ espaço vivido pelos índios Puri permitiu aos que se relacionavam ao seu cotidiano a absorção da interação de áreas onde as atuais fronteiras da Região Noroeste Fluminense se sobrepuseram. Por isso não é de se estranhar quando Cruz (2003, p.85) cita em sua tese sobre desenvolvimento e dinâmica territorial no Norte Fluminense, a existência de um imaginário local "a ideia de uma grande região, situada ao norte do ERJ, desde o litoral até Cabo Frio, abrangendo partes do território do Estado do Espírito Santo, e do Estado de Minas Gerais (...)". Cruz (2003) aponta que a sociedade local vincula essa grande região à pujança econômica original. Todavia, o destaque que se quer dar nesse artigo é que com os indícios apontados por Malheiros (2008) entenderse-á que o vínculo com essa "grande região" remonta ao circuito estabelecido, a princípio, pelos índios Puri; o qual foi sendo incorporado por ocupantes, principalmente relacionado às fazendas, permitindo mais tarde a intensificação de incursões na região e a expansão da fronteira agrícola. Observe o que Malheiros (2008) destaca:

é pertinente supor que estes índios [Puri, Coroado, Coropó] estiveram relacionados não apenas a expansão da colonização do norte fluminense, mas, também, aos processos de ocupação colonial nas áreas limítrofes com Minas Gerais, em todo curso do Paraíba do Sul, e Espírito Santo e até mesmo em áreas litorâneas. (MALHEIROS, 2008, p.144).

Não só a dinâmica estabelecida pelo circuito dos índios Puri, mas, também, a dinâmica produtiva efetivamente vivida nas fazendas contribuiu para destacar áreas que hoje compõe a Região Noroeste Fluminense. Por exemplo: a cultura do café deu destaque a municípios como Cambuci, Santo Antônio de Pádua e Itaperuna ${ }^{7}$. Em correspondência a esse fato, censos demográficos e agropecuários de 1970 apontam para uma classificação regional que compreende uma Microrregião em Campos e uma Microrregião em Itaperuna, produzindo uma diferenciação de área em relação à baixada campista por conta da produção de café; delineando, assim, pretéritos contornos da Região Noroeste Fluminense, diante aos documentos oficiais do Estado. Sofiatti considera:

(...) com a introdução da cultura do café na primeira metade do século XIX, pelos eixos de Cantagalo e Sul de Minas (Zona da Mata), consolidou-se um processo de diversificação produtiva (...) produziu uma diferenciação interna que definiu os contornos do atual Noroeste Fluminense (mais identificado, em termos produtivos, à Zona da Mata e ao Sul do Espírito Santo) (SOFIATTI, 1997. Apud. CRUZ, 2003, p. 90).

A conjuntura social entre os índios Puri e os fazendeiros, no contexto do século XIX, imprimiu uma "identidade regional objetiva" 8 . É importante salientar que essa "identidade regional objetiva", como termo utilizado para compreendermos a conjuntura social entre índios Puri e fazendeiros numa determinada área espacial e numa determinada época, extrapola a fronteira da Região Noroeste Fluminense e se transfigura aproximadamente com a "grande região" citada por Cruz (2003) - desde o litoral, abrangendo partes do território do Estado do Espírito Santo, e do Estado de Minas Gerais. Observe a figura 1 e na figura 2, o polígono representativo da área em questão: 
Figura 1

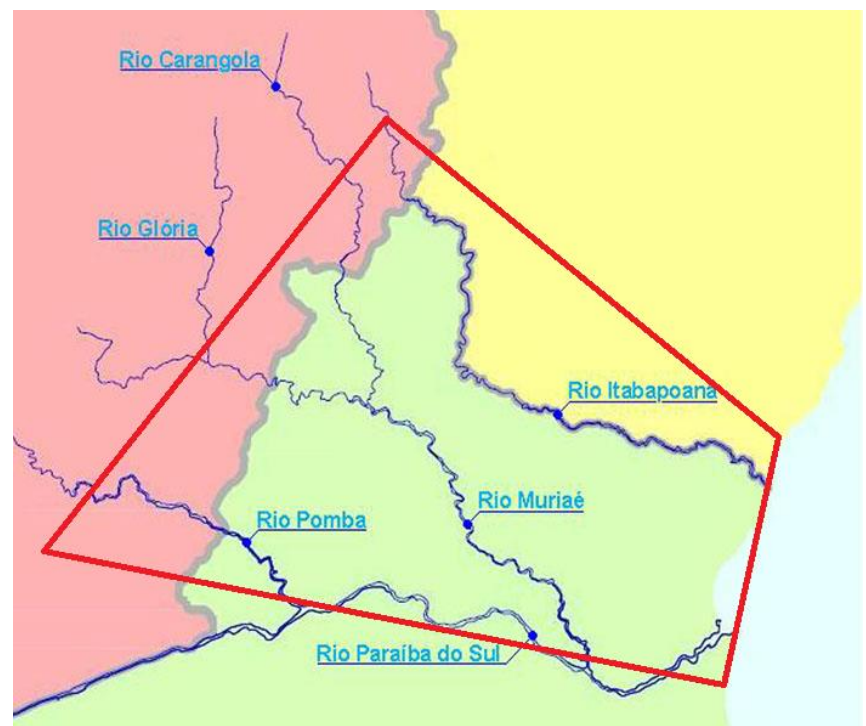

Figura 2

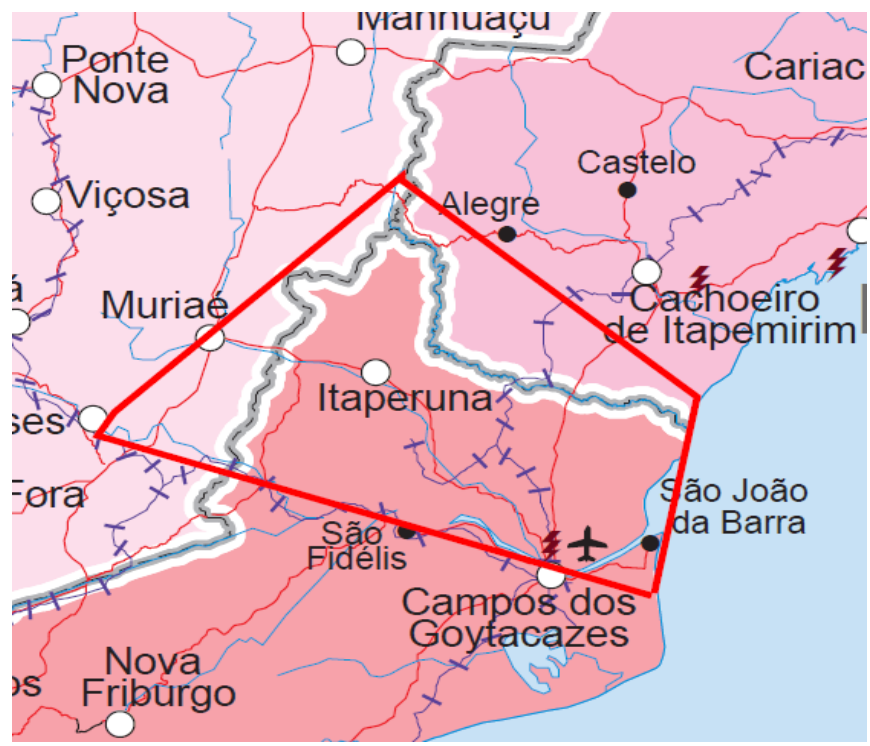

A articulação social e econômica, entre os índios Puri e fazendeiros locais, permitiu uma coesão de área: de limites pouco definidos e sobrepostos [configurada numa determinada época]. Visto que a área da "grande região" é uma representação do espaço de dimensão diversa a da região administrativa Noroeste Fluminense, mas a subentende por meio de práticas sociais pretéritas, aproximar-se-á ao conceito de Yves Lacoste de "espacialidade diferencial" - em que as práticas sociais representam confusamente multiescalas de tamanhos não semelhantes (LACOSTE, 2010, p. 47). Lacoste ressalta que é preciso compreender em relação aos fenômenos geográficos seu significado político e fazer referência "ao conjunto de práticas sociais e às diversas representações de espaço que lhe são ligadas" (LACOSTE, 2010, p. 41).

Fato é que pelos censos demográficos e agropecuários de 1970 terem apontado uma diferenciação de áreas entre a Microrregião de Campos e a Microrregião de Itaperuna, como citado acima, não só envolve fatores econômicos e históricos, mas principalmente fatores políticos consagrados desde 1850. Marcia Malheiros de certa forma exemplifica isso, quando ressalta que a catequese dos índios, através da introdução de aldeias missões, passa a ser gerida, a partir de 1861, pelo Ministério dos 
Negócios Agricultura Comércio e Obras Públicas; a fim do controle de posse de terras na região:

(...) a lei de terras de 1850 estabeleceu que os índios tivessem usufruto temporário das terras das aldeias até que atingissem o 'estado de civilização'. A partir de 1861, o encargo de catequese e civilização dos índios passou ao Ministério dos Negócios, Agricultura comércio e Obras Públicas, evidenciando que, no século XIX, a questão dos índios tornara essencialmente uma questão de terras (...). (MALHEIROS, 2008, p. 181, $356)$.

O registro de índios na região ter sumido dos documentos oficiais já a partir de 1860 retira o direito de índios como os Puri sobre terras do atual "Noroeste Fluminense", possibilitando o estabelecimento definitivo, por registros, de propriedades privadas agropastoris, e de uma microrregião econômica produtora de dividendos para $\mathrm{o}$ Estado - principalmente através da produção de café. Todavia é de se saber que a área em questão possuía também pequenos estabelecimentos, roçados, dedicados a produção de mandioca, milho e açúcar (MALHEIROS, 2008, p. 25).

REIS (2012), ainda, fazendo referência ao trabalho de Rosane Aparecida Bartholazzi de Carvalho (2009), escreve sobre agriculturas de subsistência na Região Noroeste Fluminense, pela incursão de mineiros. Bartholazzi (2009, p. 119), por sua vez, destaca o processo de partilha iniciado por José de Lanes, mineiro que em 1834, tomou posse de terras onde se originou o município de Itaperuna, deu origem a uma "estrutura fundiária formada por pequenos e médios proprietários de terra, sendo pequeno o número de grandes fazendas cafeicultoras".

Há de saber, assim, que terras antes pertencentes aos índios Coroado, Coropó e Puri, incorporaram valores sociais e políticos diferenciados na construção do espaço regional. Em um primeiro momento, enquanto terras proibidas pelas cartas régias da coroa portuguesa, justamente para coibir o contrabando aurífero do século XVIII, agregam-se as mesmas terras o significante de "Certão dos Índios Brabos". Isso, concomitante ao controle militar pela coroa, a formalização dos empreendimentos agrícolas e pastoris pela concessão de sesmarias, e a incursão de missionários capuchinhos para fundar aldeias catequizadoras; adicionando os índios a cultura das vilas para mais tarde não reconhecer-lhes o direito as mesmas terras. Em um segundo momento, a partir segunda metade do século XVIII, atribui-se as terras locais grande fertilidade, despontando na comercialização de madeira. Num terceiro momento, principalmente a partir do século XIX, e com a instituição da Lei de Terras em 1850, as quais os indígenas locais perdem o reconhecimento legal e estatutário da posse de suas terras, a produção agrícola desponta através da propriedade privada; de onde culmina a produção de café da região (MALHEIROS, 2008). O quarto momento, já em vias de futuros registros e delimitações da Microrregião de Itaperuna, no período de ascensão produtiva do café na região e sequente crise produtiva cafeeira no Brasil, e ainda mais além, pela reconfiguração dos polos produtivos com o delineamento dos complexos agroindustriais, segue-se a atribuição de referenciais de pobreza atrelados à produção agropecuária.

Percebe-se, portanto, que essa configuração histórico-social e a atribuição de significantes e significados ao objeto em questão integram-se ao artigo justamente para compreensão do espaço regional. Assim, o artigo segue considerando o processo de regionalização da Região Noroeste Fluminense aprofundando a exposição sob o referencial da agropecuária. 


\section{A REGIÃO NOROESTE FLUMINENSE SOB O REFERENCIAL DA AGROPECUÁRIA}

Um diferenciador de área comumente acionado nos trabalhos acadêmicos e em documentos oficiais do Estado em relação à Região Noroeste Fluminense e ao seu processo de regionalização é a produção agropecuária. Em contrapartida é importante reafirmar que as terras hoje reconhecidas territorialmente como Região Noroeste Fluminense pertenciam aos índios Coroado, Coropó e Puri, e que a Lei de Terras de 1850 instituiu a propriedade privada e retirou o reconhecimento estatutário da posse de terras dos indígenas locais. Nesse caso é importante salientar também, que a produtividade agropecuária na região em questão, desenvolvida pela então propriedade privada, com destaque para alta produção do café já desde 1920, deriva-se em desmatamento e desgaste dos solos, por práticas agrícolas inadequadas a um terreno predominantemente colinoso. $\mathrm{O}$ desgaste do solo afetando diretamente a produção do café, principalmente em relação ao Estado de São Paulo que desponta na produtividade, aliada a descapitalização dos produtores locais, faz a Região Noroeste Fluminense passar à margem dos grandes complexos agroindustriais; mesmo porque os programas de incentivo a agricultura do Governo Federal, em meados do século $\mathrm{XX}^{9}$, eram voltados quase exclusivamente a produtores mais capitalizados economicamente e que respondiam a estímulos rápidos de produtividade. José Graziano da Silva, por exemplo, caracteriza o Nordeste do Rio de Janeiro pelo predomínio de pequenos produtores não integrados aos complexos agroindustriais, de médios e grandes produtores, das regiões Centro-Oeste, Sudeste e Sul do país (SILVA, 1993, p. 4). Assim, considerando a conjuntura da crise do Café (1930) e o processo de modernização da agricultura no Brasil $^{10}$, outra saliência que se quer dar nesse artigo é que a diferenciação de área da Região Noroeste Fluminense através da produção agropecuária foi reordenada/reconfigurada com o processo de modernização da agricultura ou Revolução Verde.

A ressignificação do diferenciador de área pela agropecuária, na Região Noroeste Fluminense, estaria a partir do fato citado acima, diretamente relacionado ao desenvolvimento desigual e combinado, contribuindo com a marginalização de determinadas regiões produtivas ${ }^{11}$. Observe o que Neves (2006) em seu artigo "Norte Fluminense: índices de pobreza e reivindicações políticas" indica sobre o contexto produtivo regional ao final da década de 1960:

ao final da década de 1960, quando se implantou o processo de erradicação dos cafezais considerados improdutivos, toda a população aí sediada enfrentou as mesmas dificuldades e adotou assemelhadas soluções informais, notadamente a migração para os centros urbanos. Contudo, logo a seguir, os gestores técnicos do Instituto Brasileiro do Café desconsideraram as condições de produção no Estado do Rio, apontando a pecuária como atividade mais viável para substituição da produção do café. O estado do Espírito Santo foi beneficiado com programas de replantio de cafezais sob condições técnicas mais viáveis e competitivas e recebeu estímulo à diversificação agrícola. Data desse período, de intervenção diferenciada por técnicos do aparato estatal, a intensificação do discurso político que sistematiza e tenta fazer reconhecer o Norte Fluminense como uma região ampla, aglutinada pela mesma pobreza, e ainda intensificada pela falta de atenção do governo federal. (NEVES, 2006, p.10).

Além de a Região Noroeste Fluminense passar a ser reificada por uma produção agropecuária decadente, tal marginalidade é atribuída, também, aos seus respectivos produtores rurais [não integrados aos complexos agroindustriais]. Nesse sentido, 
observe como Kato (2006) considera que através da imagem da agricultura moderna solidifica-se a imagem oposta relacionada à agricultura familiar:

assim, ao mesmo tempo em que se forma no imaginário brasileiro a imagem da 'agricultura moderna', especializada, mecanizada e capitalizada, solidifica-se o seu oposto, a associação da 'agricultura familiar' ao atraso, à decadência e à pobreza. E isso se refletirá diretamente nos instrumentos de políticas públicas direcionados à agricultura familiar, tanto no que se refere a aspectos quantitativos (quantidade de programas e de recursos dispensados a cada um deles) quanto a aspectos qualitativos (na maioria das vezes, quando os instrumentos de políticas públicas voltados para a agricultura familiar não recaíam sob o modelo de ações pontuais e compensatórias, apresentavam um forte viés produtivista, numa abordagem de transferência do modelo de agricultura da Revolução Verde para a unidade familiar de produção) (KATO, 2006, p. 2).

Corroborando com o exposto acima, Carvalho e Costa (2012), por exemplo, não deixa de relacionar o advento da expressão "agricultura familiar" ao processo de modernização do campo, no Dicionário da Educação do Campo:

\begin{abstract}
a partir da denominada Revolução Verde na agricultura, iniciada em meados da década de 1950 e revivificada a partir dos anos 1980, com a expansão mundial da concepção de artificialização da agricultura e a ampliação dos contratos de produção entre as empresas capitalistas e as famílias camponesas, introduziu-se a expressão agricultura familiar, outrora de uso consuetudinário aqui e acolá, mas acentuado desde a década de 1990, e consagrada lei (Brasil, 2006) como expressão formal, porque utilizada por programas e políticas públicas governamentais.

Em 24 de julho de 2006, foi sancionada pelo presidente da República a lei $\mathrm{n}^{\circ}$ 11.326, que estabeleceu as diretrizes para a Formulação da Política Nacional da Agricultura Familiar e Empreendimentos Familiares Rurais, oficializando a expressão agricultura familiar com concepção distinta daquela da empresa capitalista no campo. (CALDART, et.al, 2012, p. 29).
\end{abstract}

Reunindo a caracterização dada por Silva (1993) ao Nordeste do Rio de Janeiro, as exposições de Kato (2006), e de Carvalho e Costa (2012), destaca-se nesse artigo que: a Região Noroeste Fluminense antes sob o diferenciador regional baseado no cultivo de café de alta produtividade passa a ser reificada pela produção agropecuária marginalizada e por produtores agropecuários vinculados (ou ainda como Kato associados) a unidades de baixa produção, em processo de descapitalização e de baixo dinamismo tecnológico ${ }^{12}$. O que poderia justificar tantos autores acadêmicos destacarem a Região Noroeste Fluminense através de: "atrasos estruturais significativos que limitam a incrementação da atividade em que foi especializada (...)" (SILVA, 1997, p. 57); ou ainda "uma região totalmente esvaziada economicamente, pelo fim da economia cafeeira (...)" (CRUZ, 2003, p. 85, 326), etc.

Essas caracterizações partem da percepção social e política de marginalização regional, referente ao desenvolvimento desigual e combinado e de livre concorrência; processo esse acelerado, nesse caso, pela modernização da agricultura no Brasil e pela abertura econômica. Por isso, a heterogeneidade de produtores da Região Noroeste Fluminense, à margem do sistema de crédito em incentivo a modernização da agricultura, e que não se equiparam tecnicamente a concorrência internacional, de uma forma ou de outra, foram classificados como fora do padrão produtivo. Muitos desses produtores, referentes à Região Noroeste Fluminense, atendiam a diversas denominações como: camponeses, pequenos produtores, agricultores de baixa renda, 
etc. E que mesmo com o surgimento do termo "agricultura familiar" para enquadrá-los, por iniciativa do Estado [pelo governo central], as antigas concepções de atrasados, não modernizados, pouco produtivos, e pobres, permaneceram; causando conflitos sobre o perfil dos agricultores familiares da região. É de extrema relevância destacar, nesse caso, que a relação da Região Noroeste Fluminense com o termo "agricultura familiar" não surge necessariamente em oposição política às formas de produção capitalista.

Nas colocações de Schneider (2008, p. 990) sobre a diversidade das formas familiares de produção na agricultura, o autor expõe que há uma generalização em torno da ideia de que o agricultor familiar "é todo aquele sujeito que vive no meio rural e trabalha na agricultura juntamente com sua família". Acrescenta que é possível encontrar uma diversidade muito grande de agricultores, obedecendo a denominações locais e regionais, como as de colono, sitiante, posseiro, morador, ribeirinho, entre outras. O autor segue dizendo que antes de 1990 os termos usualmente utilizados para qualificar essas categorias sociais eram as de pequeno produtor, produtor de subsistência ou produtor de baixa renda. Schneider ainda destaca que atualmente é comum o aparecimento de clivagens como agricultura familiar camponesa, e agronegócio familiar; para cobrir interesses políticos. E de acordo com ele, cabe aos analistas "distinguir o que é propriamente uma construção política com sentido ideológico, daquilo que é um sinal da existência de uma nova categoria na estratificação social do meio rural brasileiro" (SCHNEIDER, 2008, p. 990).

Como exposto, a modernização da agricultura deriva em uma ressignificação da referência à agropecuária para a Região Noroeste Fluminense, passando de grande produtora de café para uma posição de marginalidade em relação aos complexos agroindustriais. $\mathrm{O}$ artigo segue, no próximo item, considerando relações de poder na formulação de uma reificação pela pobreza e pela racionalização da agricultura familiar local.

\section{A REGIÃO NOROESTE FLUMINENSE SOB O REFERENCIAL DA POBREZA E DA AGRICULTURA FAMILIAR}

Principalmente a partir da crise cafeeira (1960), a caracterização da Região Noroeste Fluminense estaria relacionada aos referenciais de pobreza e falta de recursos do governo estadual e federal (acionados por discursos políticos). Neves (2006) expõe tais indícios como citamos anteriormente.

Na década de 1980, pelo fato de Campos dos Goytacazes polarizar grande parte dos recursos dos planos de modernização do governo, a fração Noroeste do Estado do Rio de Janeiro ensejou uma movimentação política em torno da constituição de um novo bloco de poder em busca de maior interlocução com as autoridades federais e estaduais (CRUZ, 2003). A constituição de um novo bloco de poder no Noroeste Fluminense culmina com o seu reconhecimento, como região através do decreto do Governador do Estado do Rio de Janeiro, Moreira Franco, em 1987. Apesar de o Noroeste Fluminense ter sido legitimado, pelo Governo Estadual, enquanto região autônoma em relação a Campos dos Goytacazes, o discurso político por parte de agentes sociais locais, destacando a pobreza, permanece nas décadas seguintes. Carolina Maria Heliodora nos favorece com indícios da década 1990, ao observar atas de reuniões dos Secretários de Agricultura da Região Noroeste Fluminense. Observe o que Heliodora (2009) aponta em sua dissertação:

“a região mais pobre do estado do Rio de Janeiro" esta era uma expressão utilizada especialmente pelos secretários de agricultura reunidos no âmbito 
do CRESMA $^{13}$ para legitimarem seus poderes de barganha junto aos outros órgãos como forma de justificar a implantação de projetos de desenvolvimento. Aos órgãos públicos federais caberia o reconhecimento da pobreza e necessidade de intervenção por parte das entidades públicas e privadas (HELIODORA, 2009, p. 53).

O exercício de agentes políticos ressaltando a estagnação econômica e a falta de desenvolvimento perdurou entre os séculos XX e XXI. Além da reificação à pobreza o termo agricultura familiar, associado comumente de acordo com o comentado acima, vem de salvaguarda desse discurso político regional para angariar verbas voltadas ao setor agrícola. Assim, o peso do termo "agricultura familiar", como diferenciador regional associado à marginalização dos produtores, passa a ser disposto no discurso político local para salientar baixos índices de desenvolvimento. Mesmo por que a oficialização da expressão agricultura familiar, segundo Horácio Martins de Carvalho e Francisco de Assis Costa, no Dicionário da Educação do Campo, teve como objetivo estabelecer critérios de enquadramento legal dos produtores rurais para obtenção de benefícios governamentais. Relacionado a esse fato, o repasse das verbas do Programa Nacional de Fortalecimento da Agricultura Familiar (PRONAF), criado em 1995 pelo Governo Federal, mobilizou agentes públicos de alguns municípios da Região Noroeste a criar Secretarias de Agricultura; por que para os municípios receberem créditos da linha de ação "PRONAF - infraestrutura" era requerida pelo governo federal, além da concentração de agricultores familiares, a criação de Conselhos Municipais de Desenvolvimento Rural (CMDR) para fins de gestão. A própria Carolina Maria Heliodora, em sua dissertação, ao analisar as atas do Conselho Regional de Secretários de Agricultura do Noroeste Fluminense (CRESMA) expõe que "durante o ano de 1997 alguns municípios onde não havia Secretaria de Agricultura, estas foram criadas, como era o caso de Itaperuna". E acrescenta que o PRONAF "fazia com que os Secretários de Agricultura [relacionados ao CRESMA] tivessem de se organizar para conseguir a 'salvação dos municípios". (HELIODORA, 2009, p. 57).

Para acrescentar, Fagner Moura da Costa discorre em seu trabalho que "segundo o Secretário de Agricultura de Porciúncula, da época, o termo agricultura familiar veio com o PRONAF, e em especial com a sua linha crédito...". Assim, o secretário, quando indagado sobre as características da agricultura no município, responde:

\footnotetext{
a agricultura familiar veio com o PRONAF (...) aqui chamávamos os produtores de micro, pequenos, médios e grandes produtores. Quando começou a "entrar" o PRONAF, crédito no município, tivemos (nós e a EMATER) que aprender o conceito, pois tínhamos que enquadrar os produtores para elaborar a DAP ${ }^{14}$. (COSTA, 2005, p. 71).
}

Kato (2006) nos permite compreender de que forma a agricultura familiar passa a caracterizar a Região Noroeste Fluminense. A autora explica que a forma inicial de organização dos agricultores familiares do Noroeste Fluminense não parte por iniciativa espontânea dos produtores em torno de um interesse comum, mas da organização de um "seguimento social" desses agricultores, com amplo incentivo das instâncias governamentais. O que vimos anteriormente com Heliodora (2009), que os Secretários de Agricultura do CRESMA mobilizaram parte da categoria de agricultores familiares para receberem recursos do PRONAF relaciona-se com que Kato (2006) descreve como: organização da sociedade civil 'de cima para baixo'. Por sua vez, Heliodora (2009) quando discorre sobre a consolidação das formas de articulação política na Região Noroeste Fluminense encabeçado pelo CRESMA, destaca que não há uma 
preocupação por parte da sociedade civil em ser autônoma em relação ao posicionamento do poder público, pois os dois compartilham do mesmo objetivo.

Reforçando o movimento de reificação da Região Noroeste Fluminense sob o viés da agropecuária, e não somente isso, mas principalmente sob o viés da agroindústria moderna, ainda na década de 1990, teríamos o processo de intervenção do Governo do ERJ com a gestão de Marcelo Alencar (1995-1998) ${ }^{15}$. Marcelo Alencar coordenou políticas de desenvolvimento regional, onde o Estado do Rio de Janeiro ficou subdividido segundo potencialidades econômicas visando atração de investimentos privados e desenvolvimento industrial. A Região Noroeste Fluminense, por sua vez, segue a luz da vocação agroalimentar ${ }^{16}$, caracterizada segundo material técnico da FIRJAN:

a principal vocação da região relaciona-se ao complexo agroalimentar representado por culturas modernas destinadas à exportação ou às indústrias processadoras de alimentos, principalmente nos setores de carne, leite, frutas e oleícolas. (FGV; SEBRAE-RJ; FIRJAN, 1998, p. 25) (apud SILVA, 2006).

Augusto Cesar Pinheiro da Silva destaca que a caracterização da Região Noroeste Fluminense "com potencial agroalimentar precisa ser entendida [...] como uma tentativa de potencialização deste setor fluminense através do processamento industrial [...] o que desconsidera a agropecuária meramente de subsistência" (SILVA, 2006, p.105), geralmente relacionada à agricultura familiar. Este autor acrescenta que em propósito da modernização desejada, as atividades de subsistência devem ser eliminadas das paisagens produtivas rurais fluminenses para que se reverta, segundo o diagnóstico, o quadro de exclusão que essas atividades sofrem. Observa-se, assim, o intuito de eliminar o "atraso" através da desestruturação das lavouras não associadas ao padrão agroalimentar desejável para uma sociedade de base urbana e pautada no consumo de alimentos beneficiados.

Cabe ressaltar que dentre as atividades consideradas como potencialidades a serem desenvolvidas no "Noroeste Fluminense", segundo o diagnóstico supracitado, estariam a olericultura e a fruticultura (SILVA, 2006, p. 105,106). Anthony Garotinho (1999-2002), Governador oriundo de Campos dos Goytacazes, Região Norte Fluminense, prossegue com o incentivo a "vocação" agroalimentar/agroindustrial proposta pelo diagnóstico da FIRJAN, com o Programa Moeda Verde - Frutificar. Assim, a referência regional atribuída ao Norte/Noroeste Fluminense em torno da produção agropecuária segue sendo reforçada em 2004 sob a égide da família Garotinho, com a governadora Rosinha Garotinho; pois o CEDRUS (Conselho Estadual de Desenvolvimento Rural Sustentável) passou a definir o Norte e Noroeste Fluminense como território rural ${ }^{17}$. Todavia, para formulação desses territórios o CEDRUS considerou a percentagem de estabelecimentos de agricultores familiares, além de: IDH médio; $\mathrm{n}^{\circ}$ de famílias assentadas; concentração de áreas reformadas; $\mathrm{n}^{\circ}$ de pescadores; organizações regionais existentes; existência de Pronaf-infraestrutura e serviços; e programas do governo estadual.

Não coincidentemente, o Governo de Sérgio Cabral segue a indução do desenvolvimento econômico através das "vocações regionais", já propostas anteriormente pela FIRJAN em parceria com SEBRAE-RJ, SENAI-RJ e SESI-RJ. Para a realização do Plano Estratégico do Estado do Rio de Janeiro (2007-2010) foram elencados mais de quarenta projetos, dentre estes apenas um projeto é direcionado à agricultura familiar - o Projeto "Rio Rural" (ALENTEJANO et. al. 2011). Dessa maneira verifica-se que a agricultura familiar continua a ser um referencial de negociação de verbas para o setor, entre os protagonistas políticos do Noroeste 
Fluminense e do Governo do Estado do Rio de Janeiro com o Governo Federal. E principalmente a partir de 2008, onde o Norte e Noroeste Fluminense adquirem status de Território da Cidadania ${ }^{18}$ consagrando a definição da região pela pobreza e escassez de infraestrutura.

Diante dos indícios apontados conclui-se que as reificações construídas em torno do que se entende por Região Noroeste Fluminense são parte integrante de uma perspectiva política do Governo do Estado do Rio de Janeiro, em coadunação com agentes locais, como os já citados Secretários de Agricultura. Objetivando arrecadação de recursos do Governo Federal por uma gestão do setor agropecuário, visando, na verdade, práticas empreendedoras de integração com a indústria fomentada pelo grupo FIRJAN dos sindicatos patronais e empresários.

\section{CONCLUSÃO}

$\mathrm{O}$ artigo reuniu, em princípio, indícios de relações socioespaciais entre os índios Coroado, Coropó e Puri com as frentes de colonização portuguesa, as quais são fundamentais para compreensão de uma coesão de área regional. De encontro com esses indícios apontados, Cruz (2003) relata-nos que no imaginário da sociedade local existe uma "grande região" situada no Norte do Estado do Rio de Janeiro; compreendida desde o litoral até Cabo Frio, abrangendo partes do território do Estado do Espírito Santo, e do Estado de Minas Gerais. Cruz (2003) aponta que a sociedade local associa essa "grande região" a uma pujança econômica; todavia, o artigo, compreende que essa "grande região" está atrelada a uma coesão de área estabelecida pelo circuito dos índios Puri, incorporado por ocupantes relacionado às fazendas e permitindo a intensificação de incursões na região e a expansão da fronteira agrícola.

Verifica-se, também, que a cultura do café permite uma diferenciação de área da região produtiva da baixada campista, pelo fato de censos demográficos e agropecuários de 1970 apontarem para uma classificação regional que compreende uma Microrregião em Campos e uma Microrregião em Itaperuna.

Fato é que tal processo de regionalização não se assume pela ordem do acaso, pelo contrário, sendo social e histórico é direcionado por intervenções políticas, tais como: incursões militares e religiosas, concessões de terras pela coroa portuguesa, e pela Lei de Terras de 1850 estabelecendo a propriedade privada e retirando legalmente o direito a posse das terras dos indígenas locais.

Esse processo de regionalização, permeado por fomento político, organiza e reorganiza os grupos sociais e acaba por derivar em (re) arranjos do espaço e no espaço interferindo diretamente nas relações de trabalho (MOREIRA, 2012, p. 17). A característica central do artigo que bem caracteriza esse princípio são os referenciais regionais, repletos de significantes e significados, que assumem intencionalidade na busca pela produção e reprodução do capital.

Verifica-se no primeiro momento que o objeto em questão esteve sob o referencial de "Certão dos Índios Brabos" [sic], pois a coroa portuguesa busca conter o contrabando aurífero das Minas Gerais. Permite com isso o controle militar regional, além da incursão missionária, e com ela a catequização dos índios para mais tarde retirar-lhes o direito às terras locais; concomitante a concessão de terras aos fidalgos. Num segundo momento, atribui-se ao objeto o referencial regional de "fertilidade" derivando a busca pela extração de madeira e maior desenvolvimento econômico local. Num terceiro momento, principalmente com a Lei de Terras de 1850, o estabelecimento da propriedade privada e a retirada do reconhecimento indígena sobre as terras locais, desponta a produção cafeeira e a diferenciação de área da baixada campista pelo 
referencial de "Microrregião de Itaperuna". É de se destacar que todos esses referenciais são de cunho estatutário e institucional. Não sendo diferente, e a partir daí, as reificações atribuídas à região: "pobreza", "descapitalização" e "infertilidade", bem como, "vocação agroalimentar". Para angariação de verbas do Governo Federal a fim de reprodução da elite política e empresarial local, bem como da concentração de terras.

Compreende-se que tais reificações, como a de "vocação agroalimentar" atreladas a projetos de planejamento estatal em parceria com instituições/corporações privadas como a FIRJAN, servem de salvaguarda às ações de controle do Estado em favor do mercado, principalmente, urbano/industrial/elitista/patronal. Conclui-se, portanto, que ações do Governo do Estado do Rio de Janeiro para o território rural em questão, não visam o direito a terra para quem quiser fazê-la produzir em prol da segurança e soberania alimentar, com redistribuição justa e racional entre pequenos agricultores, assalariados rurais, comunidades indígenas e quilombolas; e que permita, ainda, a autorreprodução dos mesmos.

\section{NOTAS}

1 - De acordo com o Censo Agropecuário de 2006 do IBGE considerando a proporcionalidade entre os estabelecimentos totais e os estabelecimentos com mais de 50 ha.

2 - O CEDRUS (Conselho Estadual de Desenvolvimento Rural Sustentável) passou a definir o Noroeste Fluminense como território rural para ação de políticas públicas, a partir de 2004.

3 - Com respeito ao rendimento médio mensal, segundo dados do IBGE 2010.

4 - Segundo a teoria de Gramsci o Estado em sentido amplo comporta duas esferas principais: a sociedade política dominante em um aparelho de Estado coercitivo; e a sociedade civil formada pelo um conjunto de organizações responsáveis pela elaboração e/ou difusão de ideologias, compreendendo inclusive partidos político e sindicatos (COUTINHO, 2012).

5 - O termo não se refere a localização geográfica, faz referencia a denominação regional do Estado do Rio de Janeiro.

6 - Grupo Macro-Jê não está relacionado com o grupo Tupi da terra Goitacá costeira.

7 - "Na década de 1920 o município de Itaperuna esteve entre o maior produtor de café do Brasil". (CRUZ, 2003, p. 88).

8 - Identidade regional objetiva refere-se "às características de natureza, cultura e dos habitantes que distinguem ou, de fato, podem ser usadas nos discursos da ciência, da política, do ativismo cultural ou da economia para distinguir a região das demais (...)". (HAESBAERT, 2010, p. 119).

9 - "No Brasil, as décadas de 1960 e 1970 são marcos da intervenção do Estado na agricultura, (...). Visando transformar o meio rural e modernizar a agricultura, inserido em uma estratégia mais ampla de desenvolvimento (...), o Estado assume de forma explícita o processo de capitalização do campo conjuntamente com o capital financeiro e industrial.". Assim para impulsionar o desenvolvimento na agricultura brasileira "Inovações mecânicas (tratores, colheitadeiras etc.), físico-químicas (adubos, agrotóxicos etc.), biológicas (plantas e sementes melhoradas) e agronômicas (alterações no espaçamento das plantas, frequência de cultivos, especialização etc.) foram adotadas para aumentar a produção e a produtividade da agropecuária brasileira" (SILVA, 1999. Apud. GRISA, 2012).

10 - Marcada pelos Complexos Agroindustriais no centro-sul do país e por cooptações de grupos sociais ligados a burguesia industrial e financeira.

11 - "A característica fundamental da chamada "modernização conservadora" da agropecuária em nosso país é, portanto, seu caráter excludente, quer se considere o tamanho dos produtores, quer se considere a região do país." (SILVA, 1993, p. 4).

12 - Quando comparado ao dinamismo tecnológico dos Complexos Agroindustriais do Centro-Sul do país - relacionado à modernização da agricultura entre as décadas de 1950/60 e vivificada nas décadas de 1970/80.

13 - Conselho Regional de Secretários de Agricultura do Noroeste Fluminense criado informalmente em 1995, pelas secretarias de agricultura de Santo Antônio de Pádua, Porciúncula, Natividade, Bom Jesus de Itabapoana, Miracema e Itaocara. Oficializou sua "criação" no ano de 1997, data de seus documentos: livro de atas e estatuto. (HELIODORA, 2009, p. 56).

14 - DAP - Declaração de aptidão ao Pronaf. Dados do Sistema de Informações Territoriais obtidos em: <http://sge.mda.gov.br/sge/index.html>. Acesso em: 27 mar. 2015. 
15 - "Com a Lei no 2.624 de 16 de setembro de 1996, o governador Marcelo Alencar consolidou em termos de administração do governo estadual, a cisão entre Norte e Noroeste Fluminense, este já compondo os treze municípios da atual divisão." (HELIODORA, 2006, p. 55).

16 - A Região Noroeste Fluminense possui a mesma configuração diante de duas classificações regionais oficiais, a do IBGE e a do Governo do Estado do Rio de Janeiro. Todavia, segundo o material técnico "Potencialidades Econômicas e Competitividade no Estado do Rio de Janeiro", idealizado pela FIRJAN, e adotado pela gestão do Governo de Marcelo Alencar, a Região Noroeste Fluminense tem outra dimensão. 17 - "Ambiente natural pouco modificado e/ou parcialmente convertido a atividades agro-silvo-pastoris; baixa densidade demográfica população pequena; base na economia primária e seus encadeamentos secundários e terciários; hábitos culturais e tradições típicas do universo rural.”. MDA/SDT (2005, p. 28). 18 - Os territórios da cidadania são definidos pela concentração de beneficiários do Programa Bolsa Família e predominância de baixo Índice de Desenvolvimento Humano (IDH) e Índice de Desenvolvimento de Educação Básica (IDEB); esses territórios alocam " $42 \%$ da demanda social do Ministério do Desenvolvimento Agrário (MDA), constituída por agricultores familiares, assentados pela reforma agrária, trabalhadores rurais que buscam acesso a terra, além de quilombolas, populações indígenas e pescadores" (NAHUM, 2010).

\section{REFERÊNCIAS BIBLIOGRÁFICAS}

ALENTEJANO, P. R. R.; BARCELOS, E. ; LEITE, L. C. F.; SANTOS, L. H.; SILVEIRA, D. M. (2011). Os grandes projetos de desenvolvimento e seus impactos sobre o espaço agrário fluminense. Terra Livre, v. 36, p. 15-40.

BARTHOLAZZI, Rosane A. Os italianos no Noroeste Fluminense: estratégias familiares e mobilidade social (1897 - 1950). Departamento de História, Universidade Federal Fluminense, Niterói, 2009.

CALDART, R. S. et.al. (2012). Dicionário da educação do campo. Rio de Janeiro: Escola Politécnica de Saúde Joaquim Venâncio.

COSTA, F. M. Da. (2005). O Plano Municipal de Desenvolvimento Rural do município de Porciúncula (RJ) e as contribuições do enfoque da multifuncionalidade da agricultura. Seropédica: UFRRJ.

CRUZ, J. L. V. (2003). Projetos nacionais, elites locais e regionalismo: desenvolvimento e dinâmica territorial no Norte Fluminense. Rio de Janeiro: Instituto de Pesquisa e Planejamento Urbano e Regional, UFRJ.

HAESBAERT, R. H. Da. (2010). Regional - global: dilemas da região e da regionalização na geografia contemporânea. Rio de Janeiro: Bertrand Brasil.

HELIODORA, C. M. (2009). O processo de "implantação" e funcionamento do Conselho Territorial do Noroeste Fluminense - CTNF: agentes, atos e representações. Seropédica: UFRRJ.

LACOSTE, Y. (2010). A Geografia: isso serve, em primeiro lugar, para fazer a guerra. Campinas: Papirus.

KATO, K. Y. M. (2006). A agricultura e o desenvolvimento sob a óptica da multifuncionalidade: o caso de Santo Antônio de Pádua (RJ). Seropédica: Instituto de Ciências Humanas e Sociais, UFRRJ.

MALHEIROS, M. (2008). Homens da fronteira índios e capuchinos na ocupação dos sertões do leste do Paraíba ou Goytacazes séculos XIII e XIX. Niterói: UFF.

MOREIRA, R. (2011). O Espaço e o contra-espaço: as dimensões territoriais da sociedade civil e do Estado; do privado e do público na ordem espacial burguesa. In: Território territórios: ensaios sobre o ordenamento territorial. Rio de Janeiro: Lamparina, p. 80, 81.

(2012). A formação espacial brasileira: uma contribuição crítica à geografia do Brasil. Rio de Janeiro: Consequência.

MARTINS, J. S.(1990). Os camponeses e a política no Brasil. Petrópolis: Vozes. 
$\overline{\text { NAHUM, J. S. (2010). Programa Territórios da Cidadania- programa de redução da }}$ desigualdade social no meio rural: as ideias fora do lugar. AGB: XVI Encontro Nacional dos Geógrafos. Porto Alegre.

NEVES, D. P. (2006). Norte Fluminense: índices de pobreza e reivindicações políticas. Revista Rio de Janeiro, n. 18-19, jan./dez.

REIS, Laudirléia Silva dos. O trabalho "precoce" dos filhos de agricultores no município de Varre-Sai - RJ. Universidade Federal Rural do Rio de Janeiro, Instituto de Ciências Humanas e Sociais, 2012.

SCHNEIDER, S.; NIEDERLE, P. A. (2008).Agricultura familiar e teoria social: a diversidade das formas familiares de produção na agricultura. In: FALEIRO, F.G; FARIAS NETO, A.L. (Org.). Savanas: desafios e estratégias para o equilíbrio entre sociedade, agronegócio e recursos naturais. 1. ed. Planaltina: Embrapa Cerrados, v., p. 989-1014.

SILVA, A. C. P. Da. (1997). Gestão e Território: O Caso da Empresa Fleischmann \& Royal no Noroeste Fluminense. Revista TERRITÓRIO, ano II, n. 3, jul./dez.

. (2006). As estratégias de modernização do espaço rural fluminense:

técnica, planejamento e gestão no campo do Rio de Janeiro. CAMPO-TERRITÓRIO: revista de geografia agrária, v. 1, n. 2, p. 92-122, ago.

SILVA, J. G. Da. (1996). Por uma reforma agrária não essencialmente agrícola. Revista Agroanalysis. v, 16, n.3, mar. . (1993). A industrialização e a urbanização da agricultura

brasileira. Em Perspectiva, São Paulo 7(3), p. 2-10, jul./set. 